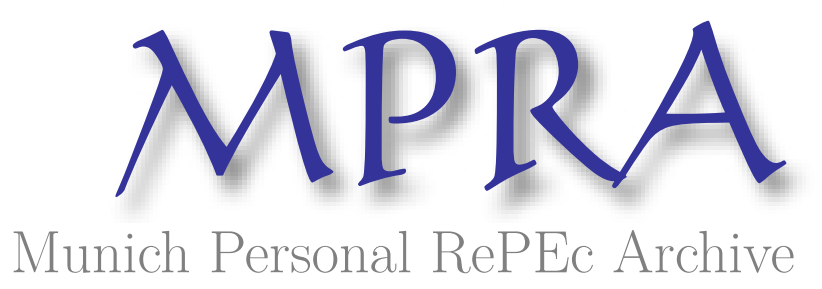

\title{
Information transmission and the emergence of a peculiar trading facility in certain emerging markets
}

Siddiqi, Hammad

11 April 2010

Online at https://mpra.ub.uni-muenchen.de/23925/

MPRA Paper No. 23925, posted 16 Jul 2010 12:52 UTC 


\title{
Information Transmission and the Emergence of a Peculiar Carry Over Transaction Facility in certain Emerging Markets
}

\author{
Hammad Siddiqi \\ Department of Economics \\ Lahore University of Management Sciences \\ hammad@lums.edu.pk
}

\begin{abstract}
A peculiar carry over transaction facility has been associated with emerging markets of India and Pakistan. We show that the trading facility can be considered a market response to the information gaps in these markets. Information can be credibly transmitted through this trading facility. Hence, the emergence of such a trading facility is, perhaps, an example of a creative market response to information problems.
\end{abstract}

Keywords: Information Asymmetry; Information Transmission; Emerging Markets; Perfect Bayesian Equilibria; Badla Finance

JEL Classification: D82; D00; G10; N20 


\section{Information Transmission and the Emergence of a Peculiar Carry Over Transaction Facility in certain Emerging Markets}

"[The information gaps] might change some of the performance characteristics, not to mention the institutional structure, of markets in which they appear."

Michael Spence, Nobel Lecture (American Economic Review, 2002)

A peculiar carry over transaction (COT) facility is associated with prominent emerging stock markets of the Indian sub-continent. In this paper, we show that it can be considered a creative market response to the information gaps existing in these emerging equity markets. The trading facility is perhaps a vehicle for credible information transmission. Hence, it serves to eliminate information gaps. In this sense, the trading facility provides one example of how information gaps change the structure of markets in which they appear.

Ever since Akerlof (1970), it has been argued that information flows are necessary for markets to function properly in a world of asymmetric information. If buyer and seller have different information regarding the value of the item to be exchanged, a "lemons market" may arise. Unable to distinguish between high-quality and low-quality goods, buyers may not be willing to pay a price that elicits the supply of anything other than the lowestquality items. Consequently, potential gains from trade may go unrealized. A large number of papers in economics and finance have identified various information transmission mechanisms operating in financial markets. See Riley (2001) for a survey. In this paper, we identify one such mechanism associated with the emerging equity markets of India and Pakistan. The mechanism operates in the form of a peculiar COT facility.

The COT facility, known as badla in local parlance, allows carry forward of open positions from one settlement date to the next. The party carrying forward its position pays a charge called the badla rate. An example clarifies. Suppose an investor buys 100 shares of stock X on Monday at Rs 1000 per share. Assume the settlement system is T+2, which means that the payment and delivery takes place two days after the transaction. That means, in our example, the investor is required to pay Rs 100,000 on Wednesday to the seller in exchange for the shares. If he does not have enough funds on Wednesday, he could defer settlement till the next settlement date (Friday) by using the following process: The badla 
financier pays the money and takes delivery from the seller ${ }^{1}$, however, at the same time, the financier sells the shares to the investor at a price in excess of Rs 100,000. Since the sale will be settled on the next settlement date, the investor benefits as his open buy position has been carried forward. The financier benefits since the purchase price is set to be in excess of Rs 100,000. The annualized percentage excess amount is termed the badla rate. The financier holds the shares as collateral till settlement.

The badla first emerged in the Bombay Stock Exchange, which is the oldest stock exchange in Asia. The Bombay Stock Exchange formally started operations in 1875. The history of badla can be traced back to that period. Badla remained in its original form in the Indian markets till the mid 90s when reforms were first introduced with an objective of better managing the default risk (Somanathan (1998)). It remained in its original form in the Pakistani markets till 2005. In its original form, badla could be used to carry forward transactions indefinitely and there were no margins. With reforms, badla trade was limited to 90 days and some margin requirements were introduced (Somanathan (1998)). However, the margin requirements were small and never exceeded 5\% in the case of Pakistan and 10\% in the case of India. Even such small margin requirements were not effectively enforced.

The key feature of badla system is the exposure of badla financier to counterparty risk. The risk is difficult to manage, between the transaction and settlement dates, since the clearing house does not guarantee this transaction. The counterparty (investor) is more likely to be forced into a default precisely when the collateral is eroded. That is, in a sharply falling market.

Badla is not a call option since the financee is obligated to pay the financier and take delivery of shares on expiry, whereas in a call option, payment and delivery is at the discretion of the buyer. Badla is not equivalent to a futures contract since, in a futures contract, exchange is the counterparty to each transaction (and enforces margin requirements), whereas, a badla contract, is effectively between a financee and a financier. Badla appears strange in the context of a spot market since it effectively superimposes a feature of the futures market (settlement in the future) onto the spot market. Badla is not like any derivative instrument (option, futures contract, or forward contract) as with a derivative

\footnotetext{
${ }^{1}$ The per-share amount paid by the financier depends on the closing price on Wednesday. In our example, we assume that this price is equal to the price on Monday for simplicity. However, if it is lower, the financier pays the lower price and the investor pays the difference.
} 
contract, the settlement price is known in advance. Whereas in badla, the final settlement price (and even the date) is unknown. Hence, unlike derivatives, badla cannot be used for hedging purposes. To our knowledge, such a carry over transaction facility has never existed in any other stock market outside of India and Pakistan.

To appreciate how peculiar this COT facility is in the context of a stock market, consider the standard leveraging instrument typically used in other stock markets; margin financing. Margin financing is a loan against shares with margin requirements and margin calls. Under margin financing, typically a broker gets a credit line from the bank, from which loans are given out to clients. An example clarifies. Suppose a client has a portfolio worth Rs. 100,000 with a broker. If the margin requirement is $50 \%$, he can get a loan of Rs 50,000 from the broker (who in turn gets it from a bank) by pledging his portfolio of Rs 100,000 as collateral. If share prices fluctuate, margin calls are made so as to keep the value gap between the shares and the loan higher than a certain percentage. In the US, minimum margin requirements are set by the Federal Reserve Board. Margin financing is a much safer instrument since exchange is involved in controlling risk through margin calls and the amount of loan given out is a fraction (typically 50\%) of the value of shares pledged as collateral. Margin financing is essentially a loan against shares already owned by the borrower. In contrast, badla, is not a loan against shares already "owned" by the borrower. It is a carry over transaction facility that typically by-passes the exchange. So, badla financier bears all the risk with hardly any margin involved. Badla facilitates a carry forward transaction in which the financier is fully exposed to the default risk whereas a margin financier is in a much more secure position since exchange manages the default risk through margin calls and margin requirements.

How large is the counterparty risk faced by the financier? The counterparty risk is significant and has resulted in various payment crises in both India and Pakistan. In one instance, in May 2000, in a chain reaction, several brokers (who were also badla financiers) in the Karachi Stock Exchange (KSE) defaulted as share prices fell and badla borrowers could not pay up. In another instance, KSE remained practically closed for several months in 2009 when a crisis linked to badla led to the imposition of a price floor. Similar crises linked to badla happened in major bourses of India too. Due to the crises caused by the counterparty risk, authorities in both India and Pakistan tried to eliminate Badla several times. In both India and Pakistan, after each ban, badla was started again in a modified form with an 
objective of better managing the counterparty risk. Eventually badla was officially banned from Indian markets in 2001, and from the Pakistani markets in 2009. However, it still continues without the official approval in both countries. ${ }^{2}$ Presently, a debate is raging in Pakistan to once again give an official nod to badla.

Typically, badla is considered a facility that relaxes the short term liquidity constraint of investors. In this paper, we argue that there is much more to the story of badla than meets the eye. We show that badla maybe a vehicle for credible information transmission from brokers (who are the main financiers) to general investors. The emergence and subsequent thriving career of badla in the sub-continent can be considered a creative market response to information gaps that plague the markets of this region.

As mentioned earlier, an interesting fact is that financiers are typically brokers. Why don't other financial institutions participate in this market, especially when such participation has been actively sought by regulators? It appears that brokers get some benefit from badla, which is not available to others. This perception is further re-enforced, when one realizes, that the official banning of badla has been fiercely resisted by the broker community whenever such a ban is proposed (Echeverri-Gent (2001)). Another feature is that badla volumes vary substantially from stock to stock but badla rates are typically the same across stocks. ${ }^{3}$

In this paper, we argue that the benefits available to the broker community are twofold from providing badla finance. One type of benefit is easy to see, however, the other type is more subtle. Firstly and quite plainly, badla finance relaxes the short-term liquidity constraint faced by certain investors. This increases the transaction volume. As brokers charge a commission on transactions, income of brokers goes up. Secondly, and perhaps, more importantly, badla is an instrument that brokers use to credibly transmit information to investors. It is likely that brokers have superior information about the value of shares. They have dedicated research departments who specialize in building networks with managers of the firms. Insider-trading is practically not considered a crime in these markets and brokers are widely believed to aggressively seek such information. Khwaja and Mian (2005) have shown that brokers make substantially large profits when they trade on their own account when compared to the gains accruing to clients when they act as intermediaries for them.

\footnotetext{
${ }^{2}$ Badla come back via margin trading, The Financial Express, Aug.19, 2002.

${ }^{3}$ Data on badla is available at www.kse.org.pk.
} 
However, whether a broker is trading on his own account or trading on behalf of a client is not public information and this way of transmitting information is not credible either for obvious reasons.

We argue that badla provides a unique and credible way of transmitting this information. The amount of badla available in each stock is public information and the broker-financier faces significant counterparty risks. The existence of counterparty risk makes information transmission credible. Furthermore, counterparty risk is lower for high value stocks when compared with low value stocks. If marginal counterparty risk is inversely related to the quality of the stock as a vehicle for badla investment, signaling equilbria can exist as the 'single crossing property' is satisfied. So by providing more badla in high value stocks, the broker-financier can credibly transmit his private information. Stocks are revalued in the light of transmitted information. Consequently, the broker's commission goes up.

If one considers the history of badla (started in Indian markets in the $19^{\text {th }}$ century), an interesting fact emerges. Badla has always been supported by the broker-community and considered an essential aspect for the proper functioning of market except for one instance in Pakistan. In early 2009, brokers at the Karachi Stock Exchange (main stock exchange in Pakistan) signed a petition calling for the official banning of badla. What were the reasons behind this sudden change of heart? We will see that an earlier decision by the regulator to cap badla volumes may have played a role. The regulator placed an upper limit on badla volume to limit the systematic risk; however, it may have had an unintended consequence of changing brokers' opinion about it, as we will see in the model.

Badla is not only useful because it transmits information and leads to proper valuation of stocks but is also directly productive to the broker-community as its leads to an expansion in trading volume due to relaxation of the short-term liquidity constraint. Hence, badla falls in the category of productive signaling. Spence (1973) introduced the idea of signaling in the context of education. The idea has been widely applied since then. However, in contrast to Spence (1973), the model presented here identifies signaling equilibria which are productive. Another example of a paper with productive signaling equilibria is BenShahar (2008), who identifies maintenance costs in the property market as a signal of private information. 
Typically, models that identify signaling equilibria usually identify non-productive equilibria. Ross (1977) identifies the management's choice of debt level as a possible indicator of true value to outsiders. Leland and Pyle (1977) point out that the amount of selffinancing by entrepreneurs can be a credible indicator of value. Bhattacharya (1979), Meyers and Majluf (1984), Vermaelen (1984), John and Williams (1985), and Miller and Rock (1985) are other examples of models in which managers successfully transmit their private information to outsiders through various credible signals. Literature on signaling is wide and varied. Some examples are Choi (2001), Lutz (1989), and Milgrom and Roberts (1986). For a survey, see Riley (2001).

The emergence of a peculiar COT facility in prominent emerging markets is an interesting phenomenon well worth studying. However, despite its interesting role, little academic research exists on the topic. To our knowledge, the only published article directly concerned with badla is Berkman and Eleswarapu (1998). They empirically study the impact of banning and re-starting badla on volumes and prices in the Bombay Stock Exchange. To our knowledge, the model presented in this paper is the first ever theoretical study aimed at explaining the emergence and subsequent thriving career of this peculiar COT facility as an information transmission mechanism.

\section{The Model}

In this section, we present a model in which there are only two types of firms. The model is generalized to infinitely many types in section 2 .

Type 1's profit is characterized by a random variable X, which is uniformly distributed on $[0, \mathrm{~d}]$, whereas type 2's profit is uniformly distributed on $[0, \mathrm{c}]$. Type 1 is superior to type 2 in the following way: $d>c$. At the beginning of each period, nature decides whether a given firm is of type 1 or type 2 . The profits are realized at the end of each period. There is a representative broker who is also a badla-financier. At the beginning of each period, he chooses how much badla to provide in each type of stock. The broker-financier observes nature's move, but the move is not observed by the market. Each firm is a going concern (lives forever). 


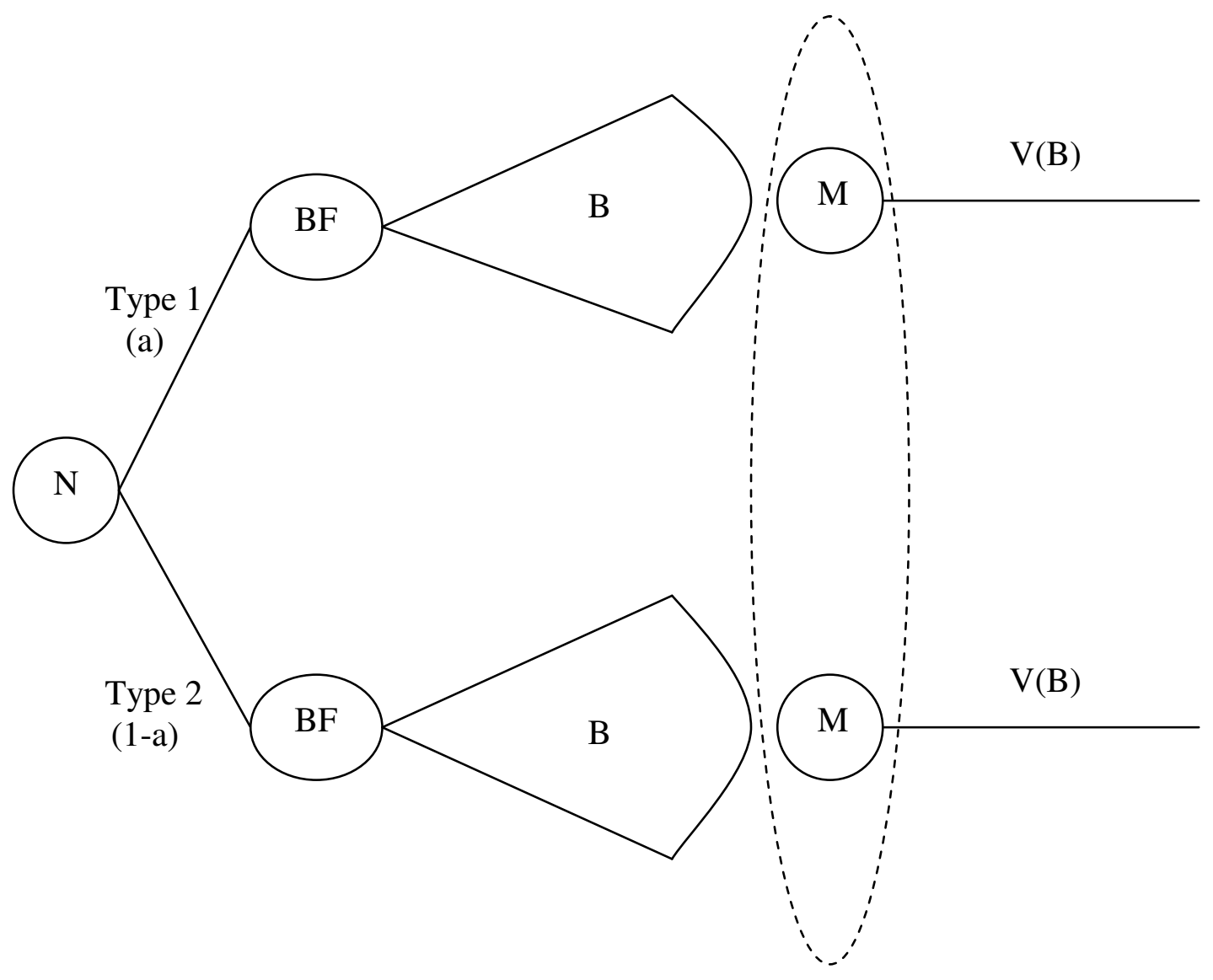

Figure 1

Figure 1 shows the game in extensive form. Three things happen at the beginning of each period. Firstly, nature $(\mathrm{N})$ makes it move and decides the type of a given firm. The move is observed by the broker-financier but not by the market. Secondly, the brokerfinancier (BF), chooses the amount of badla finance (B) to provide. This move is observed by the market. Thirdly, market (M) determines the value of the firm $(\mathrm{V}(\mathrm{B}))$ and in doing so indirectly affects the commission income of the broker. At the end of the period, profit of the given firm is realized. The frequency of type 1 firms is assumed to be 'a', with $a<1$, at any give point in time, so frequency of type 2 firms is ' 1 -a'. Without any loss of generality, we assume, $\mathrm{a}=0.5$.

Figure 2 shows a particular instance of the game over two time-periods. As can be seen, nature makes a move (at time 0 ) and decides that the firm is of type 1 . So, its profit is realized, at time 1 , from the interval $[0, \mathrm{~d}]$. The nature moves again and decides, at time 1 , 


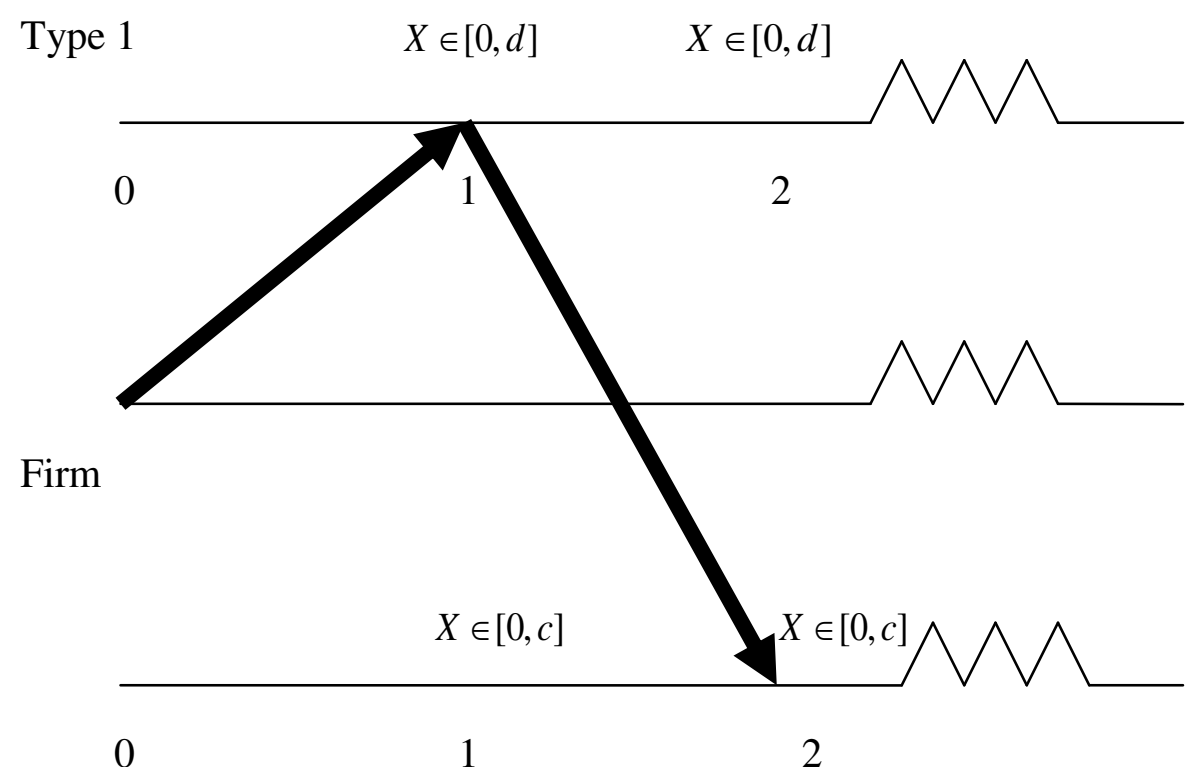

Type 2

Figure 2

that the firm is of type 2. Consequently, its profit is realized from the interval $[0, c]$ at time 2 . The game continues each period with the type randomly decided at the beginning of each period and profits appropriately drawn at the end of each period. Firms are dynamic entities and their profitability is never a constant. Fluctuation in type can be interpreted as changes in the environmental factors affecting a firm's profitability.

If at time 0 , the type of a given firm is revealed as type 1 , its market value is:

$V_{1}=\frac{d}{2(1+r)}+\frac{c+d}{4 r(1+r)}-\frac{\lambda}{(1+r)}$

Where $\lambda$ is the coefficient of risk aversion, and $r$ is the discount rate.

Similarly, the market value of a type 2 firm is:

$V_{2}=\frac{c}{2(1+r)}+\frac{c+d}{4 r(1+r)}-\frac{\lambda}{(1+r)}$

Clearly, $V_{1}>V_{2}$. 
We assume (without any loss of generality) that, in the beginning of each period, the total volume of transactions processed by the broker in each firm, in the absence of badla financing, is exactly equal to the market value of the firm,

That is,

Commission Income $=f \cdot V$

Where $0<f<1$ represents the commission percentage (usually $2 \%$ ) of the broker.

Apart from intermediating, the broker is also a badla financier. Broker-financier provides badla for one period. Badla relaxes the short-term liquidity constraint faced by the market; hence, it enhances the trading volume. Consequently, the broker-financier's commission income goes up:

Commission Income $=f \cdot V(B)+f \cdot B$

Equation (4) shows that badla is not only a potential signal (as it may transmit information) but is also productive for the broker as it directly increases his commission income.

However, badla creates counterparty risk for the broker-financier. Badla is a debt given by the broker-financier to the market. If the profit realized at the end of the period is large enough to cover badla payment along with interest on badla, $i$, the broker-financier gets his money back along with interest, otherwise he may lose a part/all of interest or/and a part/all of his badla investment. In general, there are three possibilities:

$$
\begin{array}{ll}
\text { If } X \geq B+i B, & \text { Badla Income }=i B \\
\text { If } B \leq X<B+i B, & \text { Badla Income }=X-B \\
\text { If } X<B, & \text { Badla Loss }=B-X
\end{array}
$$

Using $k$ to denote the type of the firm, that is, $k \in\{c, d\}$, expected badla income is:

$$
\begin{aligned}
& \text { Expected Badla Income }=\int_{0}^{B}(X-B) \frac{1}{k} d X+\int_{B}^{B+i B}(X-B) \frac{1}{k} d X+\int_{B+i B}^{k} i B \frac{1}{k} d X \\
& \Rightarrow \text { Expected Badla Income }=i B-\frac{B^{2}(1+i)^{2}}{2 k}
\end{aligned}
$$

So, total payoff of the broker-financier is: ${ }^{4}$

$$
\pi=f \cdot V(B)+f \cdot B+\frac{1}{(1+r)}\left\{i B-\frac{B^{2}(1+i)^{2}}{2 k}\right\}
$$

\footnotetext{
${ }^{4}$ Here, we have assumed that the broker-financier is risk neutral. The analysis can easily be extended to the case of a risk averse broker-financier, however, such an extension does not add any value to the analysis.
} 
In practice, the badla rate $i$, is typically not too high from the risk-free rate. The badla market does not get much attention from banks, DFIs, and other financial institutions lending support to the theory that the badla market is not attractive in its own right. It is likely that it serves some other purpose (signaling?) for the broker-financier. Given that the commission percentage is small (typically $2 \%$ ), and due to the low return on badla, we assume that badla market is not attractive enough in its own right for the broker-financier. Specifically, we assume:

$f \cdot B+\frac{1}{(1+r)}\left\{i B-\frac{B^{2}(1+i)^{2}}{2 k}\right\}<0$

Or equivalently,

$i \leq \bar{i}$

where $\bar{i}=\left(\frac{k}{B}-1\right)+\sqrt{\left(\frac{k}{B}-1\right)^{2}+\left\{\frac{2 k f(1+r)}{B}-1\right\}}$

Here, we have assumed that the broker-financier does not trade on his own behalf. This is a simplification only and does not affect the results. If we allow the broker-financier to trade on his own account then the incentive to signal the high type will be stronger due to the capital gains accruing to him from his own position. For example, if the total funds available with the broker-financier are I, and the badla amount needed to signal the high type is B, it is optimal for him to invest I-B in the high type.

So, badla financing is costly to the broker-financier due to the counterparty default possibility. And, return on badla is not large enough to counter it. However, badla is relatively more costly for the lower type (type 2). Can this difference in cost lead to credible transmission of information?

Proposition 1 provides an answer.

Proposition 1 A separating equilibrium exists in which the broker-financier provides a positive amount of badla finance in type 1 and no badla finance is provided in type 2. The market correctly infers the type of each firm in equilibrium. The amount of badla provided in type 1 is $\bar{B}=c\left\{\frac{i+(1+r) f}{(1+i)^{2}}\right\}+\sqrt{c^{2}\left\{\frac{i+(1+r) f}{(1+i)^{2}}\right\}^{2}+\frac{2 c f(1+r)\left(V_{1}-V_{2}\right)}{(1+i)^{2}}}$ 
Proof. In general, the following steps are involved in identifying a perfect Bayesian equilibrium (separating equilibrium is one example):

1) Specify beliefs of the receiver (market in our case).

2) Propose a strategy profile

3) Check to see that the strategy profile involves the best response of each player and the beliefs of the receiver satisfy Bayes rule.

In our case, market's beliefs are specified as:

$P[$ Firm $=$ Type $1 \mid B \geq \bar{B}]=1$ and $P[$ Firm $=$ Type $2 \mid B<\bar{B}]=1$

The proposed strategy profile is:

Commission Income $(B \geq \bar{B})=f \cdot V_{1}+f \cdot B$ and Commission Income $(B<\bar{B})=f \cdot V_{2}+f \cdot B$

Badla provided in type $1=\bar{B}$ and Badla provided in type $2=0$

For a separating equilibrium to exist, it must be true that the broker-financier has no incentive to deviate from providing no badla in type 2 to providing badla equal to $\bar{B}$ in type 2 . That is, the following inequality must be satisfied:

$f \cdot V_{1}+f \cdot \bar{B}+\frac{1}{(1+r)}\left\{i \bar{B}-\frac{\bar{B}^{2}(1+i)^{2}}{2 c}\right\} \leq f \cdot V_{2}$

The right hand side of the above inequality is the payoff to the broker-financier if he provides no badla and the left hand side is his payoff from providing badla equal to $\bar{B}$ in type2.

The inequality is binding at

$$
\bar{B}=c\left\{\frac{i+(1+r) f}{(1+i)^{2}}\right\}+\sqrt{c^{2}\left\{\frac{i+(1+r) f}{(1+i)^{2}}\right\}^{2}+\frac{2 c f(1+r)\left(V_{1}-V_{2}\right)}{(1+i)^{2}}}
$$

The broker-financier will not exceed the threshold specified by (10) in type 2. So, if badla slightly in excess of $\bar{B}=c\left\{\frac{i+(1+r) f}{(1+i)^{2}}\right\}+\sqrt{c^{2}\left\{\frac{i+(1+r) f}{(1+i)^{2}}\right\}^{2}+\frac{2 c f(1+r)\left(V_{1}-V_{2}\right)}{(1+i)^{2}}}$ is provided in type- 1 , and no badla is provided in type 2 (since providing badla in type- 2 will further lower 
the income of the broker-financier), then full discrimination of the types takes place and a separating equilibrium exists. Providing $\bar{B}$ in type 1 is feasible since $\mathrm{d}>\mathrm{c}$ implying $f \cdot V_{1}+f \cdot \bar{B}+\frac{1}{(1+r)}\left\{i \bar{B}-\frac{\bar{B}^{2}(1+i)^{2}}{2 d}\right\}>f \cdot V_{2}$.

Badla finance, as an instrument, can be used to credibly transmit information, as the model shows. In this sense, it can be considered a creative market response to the information gaps existing in prominent emerging markets of South Asia.

In emerging markets, the question of information transmission becomes even more important since legal and institutional preconditions for proper information flow as pointed out in Black (2001) typically do not exist. It is clear, even to a causal observer, that ground realities in emerging markets are very different from the developed markets. How do these markets respond? How do they continue to function? Perhaps, emerging markets respond by developing innovative information transmission mechanisms. That is, mechanisms unique to them. Badla is one example of an endogenously emerged mechanism that may serve the crucial need of information transmission.

Next, we show that there also exists a continuity of pooling equilibria in which no information transmission takes place.

\section{Proposition 2 There exists a continuity of pooling equilibria in which no information} transmission takes place. Each point in the interval $\left[0, B^{*}\right]$ can support a pooling equilibrium. $B^{*}=\left\{\frac{i+f(1+r)}{(1+i)^{2}}\right\} c+\sqrt{c^{2}\left\{\frac{i+f(1+r)}{(1+i)^{2}}\right\}^{2}+\frac{2 c \cdot f(1+r)}{(1+i)^{2}}\left\{\frac{V_{1}+V_{2}}{2}-V_{2}\right\}}$

Proof. As mentioned in the proof of proposition 1, there are three steps in identifying perfect Bayesian equilibria. In this case, beliefs of the receiver (market) are:

$$
P\left[\text { Firm }=\text { Type } 2 \mid B \neq B^{*}\right]=1, P\left[\text { Firm }=\text { Type } 1 \mid B=B^{*}\right]=0.5 \text { and } P\left[\text { Firm }=\text { Type } 2 \mid B=B^{*}\right]=0.5
$$

The proposed strategy profile is: 
Commission Income $\left(B=B^{*}\right)=f \cdot \frac{V_{1}+V_{2}}{2}+f \cdot B^{*}$ and Commission Income $\left(B \neq B^{*}\right)=f \cdot V_{2}+f \cdot B$ Badla provided in type $1=B^{*}$ and Badla provided in type $2=B^{*}$

Given that the most tempting deviation for the broker-financier in type 2 from $B^{*}$ is to 0 , the value of $B^{*}$ is determined from the incentive constraint faced by the broker-financier in type 2 as follows:

$f \cdot \frac{V_{1}+V_{2}}{2}+f \cdot B^{*}+\frac{1}{(1+r)}\left\{i B^{*}-\frac{B^{* 2}(1+i)^{2}}{2 c}\right\}=f \cdot V_{2}$

In (11), the R.H.S is the broker-financier's payoff from providing no badla in type 2. The L.H.S. is the broker-financier's payoff from providing badla equal to $B^{*}$. Solving for $B^{*}$ :

$$
B^{*}=\left\{\frac{i+f(1+r)}{(1+i)^{2}}\right\} c+\sqrt{c^{2}\left\{\frac{i+f(1+r)}{(1+i)^{2}}\right\}^{2}+\frac{2 c \cdot f(1+r)}{(1+i)^{2}}\left\{\frac{V_{1}+V_{2}}{2}-V_{2}\right\}}
$$

Beyond this value, the broker-financier has an incentive to deviate from the pooling equilibrium in type 2 .

\section{Corollary 1 The pooling equilibrium at $B=0$ is superior to other pooling equilibria from the point of view of the broker-financier.}

Proof. Follows directly from the assumption $f \cdot B+\frac{1}{(1+r)}\left\{i B-\frac{B^{2}(1+i)^{2}}{2 k}\right\}<0$.

We mentioned in the introduction that, quite extra-ordinarily, brokers at the Karachi Stock Exchange signed a petition, in early 2009, calling for the elimination of badla. . Perhaps, in the light of our model, the earlier decision to cap badla volumes may have played a role. Since $B^{*}<\bar{B}$, plausibly badla capping might have forced a pooling equilibrium. As pooling at $\mathrm{B}=0$ is better for the broker-financier, enthusiasm for badla, in the broker community, subsequently faded.

So far, we have discussed the model with two types only. The model can be generalized to include infinitely many types. This is done in the next section. 


\section{The General Model with Infinitely Many types}

Finding pooling equilibria for infinitely many types is straightforward as we only need the incentive constraint of the broker-financier in the lowest type (as shown in proposition 2). The pooling equilibria essentially remain the same.

To find a separating equilibrium, we assume that the types are characterized by a random variable, $K$, uniformly distributed on an interval [c , d]. As before, the brokerfinancier knows the types of all firms whereas outsiders (market) do not have this information. The game remains essentially the same with one difference. Instead of choosing from two types in the beginning of each period, nature now chooses from infinity many types.

Proposition 3 identifies a unique separating equilibrium.

Proposition 3 A unique separating equilibrium exists in which the types are correctly revealed by the amount of badla financing provided:

$K(B)=-\left\{(1+r)+\frac{i}{f}\right\} B+\sqrt{\left\{\left[(1+r)+\frac{i}{f}\right] B-c\right\}^{2}+2\left\{\frac{B^{2}(1+i)^{2}}{f}\right\}}$

Proof. The broker-financier solves the following optimization problem in each type of stock. He chooses B to maximize his total payoff in each stock.

$$
\begin{aligned}
& \pi=f \cdot V(B)+f \cdot B+\frac{1}{(1+r)}\left\{i B-\frac{B^{2}(1+i)^{2}}{2 k}\right\} \\
& \Rightarrow \frac{d \pi}{d B}=f \cdot \frac{K^{\prime}(B)}{2(1+r)}+f+\frac{1}{(1+r)}\left\{i-\frac{B(1+i)^{2}}{K}\right\}
\end{aligned}
$$

The first order condition is:

$$
f \cdot \frac{K^{\prime}(B)}{2(1+r)}+f+\frac{1}{(1+r)}\left\{i-\frac{B(1+i)^{2}}{K}\right\}=0
$$

By re-arranging the first order condition:

$$
K \cdot K^{\prime}(B)+2 K(1+r)+\frac{2 K i}{f}=\frac{2 B(1+i)^{2}}{f}
$$




$$
\begin{aligned}
& \Rightarrow K \cdot \frac{d K(B)}{d B}+2 K(1+r)+\frac{2 K i}{f}=\frac{2 B(1+i)^{2}}{f} \\
& \Rightarrow \int K \cdot d K(B)+\int\left\{2 K(1+r)+\frac{2 K i}{f}\right\} d B=\int \frac{2 B(1+i)^{2}}{f} d B \\
& \Rightarrow \frac{K^{2}}{2}+\int\left\{2 K(1+r)+\frac{2 K i}{f}\right\} d B=\frac{B^{2}(1+i)^{2}}{f}+z
\end{aligned}
$$

where $z$ is the constant of integration.

The middle term can be re-arranged as:

$$
\left\{2(1+r)+\frac{2 i}{f}\right\} \int K(B) d B
$$

$\sin c e K^{\prime}(B)$ can be approximated as $\frac{K(B)-K(0)}{B}$, we have

$$
K(B)=K^{\prime}(B) B+K(0)
$$

So,

$$
\left\{2(1+r)+\frac{2 i}{f}\right\}\left\{\int K^{\prime}(B) B d B+\int K(0) d B\right\}
$$

Since there is no incentive to signal the lowest type, $K(0)=c$

Hence,

$$
\left\{2(1+r)+\frac{2 i}{f}\right\}\left\{\int K^{\prime}(B) B d B+c B\right\}
$$

Using integration by parts,

$$
\int K^{\prime}(B) B d B=\int \frac{d K(B)}{d(B} B \cdot d B=\int B d K(B)=B \cdot K(B)-\int K(B) \cdot d B
$$

Substituting (14) in (13),

$$
\begin{aligned}
& \left\{2(1+r)+\frac{2 i}{f}\right\}\left\{\int K^{\prime}(B) B d B+c B\right\}=\left\{2(1+r)+\frac{2 i}{f}\right\}\left\{B \cdot K(B)-\int K(B) d B+c B\right\} \\
& \Rightarrow\left\{2(1+r)+\frac{2 i}{f}\right\}\left\{B \cdot K(B)-\int K(B) d B+c B\right\}=\left\{2(1+r)+\frac{2 i}{f}\right\} \int K(B) d B \\
& \Rightarrow \int K(B) d B=\frac{B \cdot K(B)+c B}{2}
\end{aligned}
$$

It follows,

$$
\left\{2(1+r)+\frac{2 i}{f}\right\} \int K(B) d B=\left\{2(1+r)+\frac{2 i}{f}\right\} \frac{B \cdot K(B)+c B}{2}
$$


Substituting (15) in (12),

$$
\begin{aligned}
& \frac{K(B)^{2}}{2}+\int\left\{2 K(B)(1+r)+\frac{2 K(B) i}{f}\right\} d B=\frac{B^{2}(1+i)^{2}}{f}+z \\
& \Rightarrow \frac{K(B)^{2}}{2}+\left\{2(1+r)+\frac{2 i}{f}\right\} \frac{B \cdot K(B)+c B}{2}=\frac{B^{2}(1+i)^{2}}{f}+z
\end{aligned}
$$

Since there is no incentive to provide a signal in the lowest type, that is, $B=0$ for the lowest type, we have:

$z=\frac{K(0)^{2}}{2}=\frac{c^{2}}{2}$

So, (16) becomes,

$$
\frac{K(B)^{2}}{2}+\left\{2(1+r)+\frac{2 i}{f}\right\} \frac{B \cdot K(B)+c B}{2}=\frac{B^{2}(1+i)^{2}}{f}+\frac{c^{2}}{2}
$$

Finally, solving for $\mathrm{K}(\mathrm{B})$,

$$
\begin{aligned}
& K(B)=-\left\{(1+r)+\frac{i}{f}\right\} B+\sqrt{\left\{(1+r)+\frac{i}{f}\right\}^{2} \times B^{2}+2\left\{\frac{B^{2}(1+i)^{2}}{f}\right\}+c^{2}-2 c B\left\{(1+r)+\frac{i}{f}\right\}} \\
& K(B)=-\left\{(1+r)+\frac{i}{f}\right\} B+\sqrt{\left\{\left[(1+r)+\frac{i}{f}\right] B-c\right\}^{2}+2\left\{\frac{B^{2}(1+i)^{2}}{f}\right\}}
\end{aligned}
$$

(18) permits full discrimination of types and there is no incentive to signal a false type.

Badla has been banned in both India and Pakistan, primarily, because of the ripple effects of the counterparty risk. When badla borrowers default, broker-financiers are hit, and if brokers default as a result, it causes panic. So, the counterparty risk embedded in badla finance directly contributes to the systematic risk. Consequently, the overall risk perception of the market is adversely affected. However, badla has its benefits too, primarily, it may serve the purpose of information transmission as identified in this paper. The emergence and long life of badla is an example of market's ability to find creative solutions when faced with serious information asymmetries. Perhaps, other emerging markets, have responded in their own unique ways, and found ways to transmit information. 


\section{Conclusion}

We have considered a peculiar COT facility associated with prominent equity markets in South Asia. The instrument known as badla may actually be an institutional response to the information gap existing in these markets. The information gaps in these emerging markets tend to be fairly serious since legal and institutional pre-conditions for proper information flows are not present in these markets. Badla may serve a useful purpose by eliminating such information gaps.

Information transmission is a serious consideration, especially for emerging markets as severe information asymmetries are likely to exist in developing markets. The model presented here illustrates that, perhaps, these markets are responding to the challenge in their own unique ways. Identifying such mechanisms in other emerging markets is an interesting task for future research. 


\section{References}

Akerlof, George A. (1970), “The Market for 'Lemons': Quality Uncertainty and Market Mechanism", Quarterly Journal of Economics, Vol. 84, 3, 488-500.

Ben-Shahar, D. (2004), "Productive Signaling Equilibria and Over-Maintenance: An Application to Real Estate Market", The Journal of Real Estate Finance and Economics, 28, 255271.

Berkman, H. and Eleswarapu, Vinket R. (1998), "Short-term Traders and Liquidity: A Test using Bombay Stock Exchange Data”, Journal of Financial Economics, 47, 339355.

Bhattacharya, S. (1979), "Imperfect Information, Dividend Policy, and 'the Bird in the Hand Fallacy” ", Bell Journal of Economics, 10, 259-270.

Black, B. (2001), “The Legal and Institutional Preconditions for Strong Stock Markets”, UCLA Law Review, 48, 781-855.

Choi, J. P. (2001). "Planned Obsolescence as a Signal of Quality," International Economic Journal 15, 59-79

Echeverri-Gent, J. (2002), "Politics of Market Microstructure: Reforming India's Equity Market Institutions", Paper presented at the annual meeting of American Political

Science Association, http://www.allacademic.com/meta/p65338 index.html.

John, K. and William J. (1985), "Dividends, Dilution and Taxes", Journal of Finance, 40, 1053-1070.

Khwaja, A., and Mian, A. (2005), "Unchecked Intermediaries: Price Manipulation in an Emerging Market”, Journal of Financial Economics,

Leland, H. and Pyle, D. (1977), "Information Asymmetries, Financial Structure, and Financial Intermediation", Journal of Finance, 32, 371-387.

Lutz, N. A. (1989). "Warranties as Signals under Consumer Moral Hazard," Rand Journal of Economics 20, 239-255

Meyers, S. and Majluf, N. (1984), "Corporate Financing and Investment Decisions when Firms have Information that Investors do not have", Journal of Financial Economics, 13, 187-221.

Milgrom, P., and J. Roberts. (1986). "Prices and Advertising Signals of Product Quality," Journal of Political Economy 94, 796-821

Miller, Merton H., and Rock, K. (1985), "Dividend Policy under Asymmetric Information", Journal of Finance, 40, 1031-1051. 
Somanathan, T. V. (1998), Derivatives. Tata-McGraw Hill Publishing Company

Spence M. (1973), “.Job Market Signaling”, Quarterly Journal of Economics 87, 355-374

Riley, J. (2001), "Silver Signals: Twenty-Five Years of Screening and Signaling”, Journal of Economic Literature 39(2), 432-478.

Ross, Stephen A. (1977), "The Determination of Financial Structure: The Incentive Signaling approach”, Bell Journal of Economics, 8, 23-40.

Vermaelen, T. (1984), "Repurchase Tender Offer, Signaling, and Managerial Incentives", Journal of Financial and Quantitative Analysis, 163-181. 